\title{
Stuck on phosphines
}<smiles>O=Cc1ccc(P(c2ccc(C=O)cc2)c2ccc(C=O)cc2)cc1</smiles><smiles>Nc1ccc(N)cc1</smiles>

Covalent organic frameworks (COFs) are promising candidates as support for metal nanoparticles, due to their porous structures combined with the possibility to incorporate diverse functional groups. However, controlling the distribution of metal species in the framework remains challenging. Now, Li Qiu, Wei Zhang and colleagues introduce a phosphinefunctionalized crystalline COF as support for the preparation of monometallic, as well as bimetallic, metal nanoparticles with narrow size distribution, which can be employed for different catalytic transformations.

The framework, which features high crystallinity and a surface area of 818 $\mathrm{m}^{2} \mathrm{~g}^{-1}$, is obtained via condensation of a triphenylphosphine-based tri-aldehyde with $p$-phenylenediamine (pictured). The authors surmised that the phosphine functionalities periodically distributed throughout the

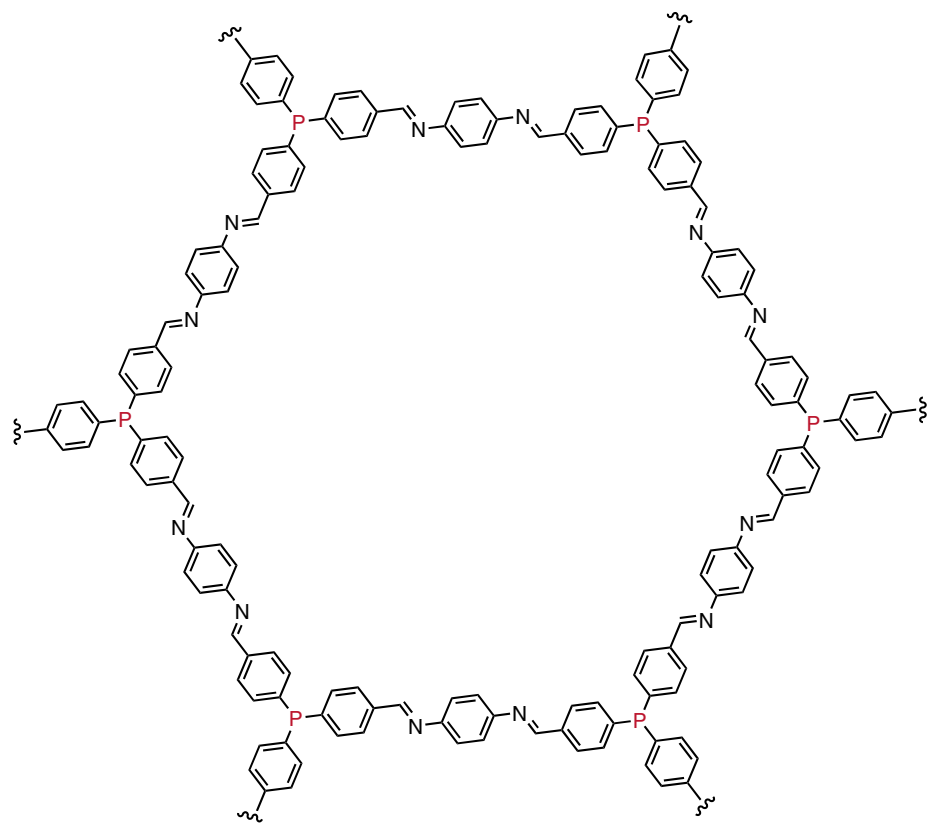

material would function as coordination sites to direct nanoparticle nucleation and growth. In fact, reducing a suspension of the solid in a methanol solution of $\mathrm{K}_{2} \mathrm{PdCl}_{4}$ with $\mathrm{NaBH}_{4}$ leads to the formation of $\mathrm{Pd}$ nanoparticles highly dispersed within the pores of the material. Interestingly, the method also works for $\mathrm{Pt}, \mathrm{Au}$, and bimetallic PdAu nanoparticles, which in all cases feature a narrow size distribution with diameter below $2 \mathrm{~nm}$. The loading of the metal is a key parameter to control particle size during synthesis.

The resulting $\mathrm{Pd} / \mathrm{COF}$ proves to be an excellent catalyst for the Suzuki-Miyaura coupling of different aryl bromides and iodides with phenylboronic acid. The composite outperforms common palladium salts or heterogeneous Pd catalysts such as $\mathrm{Pd} / \mathrm{C}$, resulting in larger turnover frequencies under comparable conditions. Moreover, recycling experiments confirmed the stability of the catalyst over multiple reaction cycles while transmission electron microscopy revealed an essentially unaltered particle distribution after use. The authors also evaluated the performance of the $\mathrm{Pt}$ and $\mathrm{Au}$ containing catalysts using the reduction of nitrophenol and 1-bromo-4nitrobenzene, respectively, as test reactions. Finally, the composite based on bimetallic $\mathrm{PdAu}$ was tested for the tandem reduction of $p$-nitroiodobenzene followed by coupling with phenylboronic acid. In general, the good catalytic performance of this series of composites confirms the generality of the approach and the ability of COFs to serve as tunable supports for the preparation of heterogeneous catalysts.

\section{Davide Esposito}

Published online: 19 February 2020 https://doi.org/10.1038/s41929-020-0437-x 